\title{
Kıyaslamanın (Benchmarking) ve Öğrenmenin Aracı Bir Unsuru Olarak Kardeş Kent Uygulaması ${ }^{1}$
}

\author{
Sister City Practice as a Factor of Benchmarking and Learning
}

Koray KURUTÇU

Blm. Uzm., Giresun Üniversitesi, SBE,

kurutcu-93@hotmail.com

https://orcid.org/0000-0003-0666-5014

\section{Levent MEMIŞ}

Dr. Öğr. Üyesi., Giresun Üniversitesi, İ̈BF,

Siyaset Bilimi ve Kamu Yönetimi Bölümü,

levent_memis@hotmail.com

https://orcid.org/0000-0002-5438-691X
Makale Başvuru Tarihi: 12.02.2020

Makale Kabul Tarihi: 06.05.2020

Makale Türü: Araştırma Makalesi

$\begin{aligned} & \text { Anahtar } \\ & \text { Kelimeler: }\end{aligned}$
Kiyaslama,
Öğrenen Örgüt,
Kardeş Kent,
Trabzon
Büyükssehir
Belediyesi,

\section{Anahtar}

Belediyesi,

Keywords:
Benchmarking,
Learning
Organization,
Sister City,
Trabzon
Metropolitan
Municipality,

\section{ÖZET}

Yerelde karşılaşılan sorun ve ihtiyaçlar, yerel yönetimlerin farklı ölçeklerde, biçimsel veya biçimsel olmayan iş birliklerini gündeme getirmektedir. Yerel yönetimler arası biçimsel bir iş birliği olan kardeş kent uygulaması, özellikle İkinci Dünya Savaşı sonrası toplumlar arasında barışı ve huzuru sağlamak amacıyla desteklenmiştir. Zaman içinde Batı Avrupa ülkelerinin dışına çıkarak dünya genelinde karşılık bulmaya başlamıştır. Bu araştırmada kardeş kent uygulaması, kentler arasında klyaslamanın ve öğrenmenin aracı bir unsuru olarak konumlandirılmaktadır. Bu bağlamda çalışmanın temel amacı, kardeş kent uygulamasını, kentler arasında klyaslamanin ve ögrenmenin aracı bir unsuru olarak incelemektir. Bu inceleme Trabzon Büyükşehir Belediyesi (TBB) 'nin kardeş kent ilişkisi içinde olduğu Zigetvar ve Dortmund kentleri üzerinden gerçekleştirilmektedir. Araştırmada her iki kentin özgün tarafları üzerinden kültürel ve ekonomik birtakım faaliyetler yürütülmekle ve kısmen bazı klyaslama ve öğrenme işlevi görülmekle birlikte, ortaya çıkan bazı sinırlılıklar (iş birliklerinin devamlılı̆̆ını sağlayan aktif bir çabanın gösterilmemesi, daha çok kente odaklanan çalı̧̧malara ağırlık verilmesi, iş birliği çalı̧̧malarının proje temelli yürütülmemesi, bu faaliyetleri yerine getirecek insan kaynă̆ ve örgütlenme yetersizliklerinin varllğı, bütçe yetersizlikleri vb.) altında etkin bir durumun olmadı̆ $\breve{l}$ tespit edilmektedir.

\section{ABSTRACT}

Problems and needs that are encountered locally brings local governments to different agenda, formal or informal collaborations at different quarters. The sister city practice, which is a formal cooperation between local governments, was supported especially in order to provide peace among the societies after the Second World War. In time, it started to find a worldwide response by going out of Western European countries. In this study, sister city practice is positioned as a mediator of comparison and learning between cities. In this context, the main purpose of the study is to examine the sister city practice as a mediator of comparison and learning between cities. This investigation is carried out through the cities of Zigetvar and Dortmund, where Trabzon Metropolitan Municipality (TBB) has a sister city relationship. In the research, it is determined that some cultural and economic activities are carried out on the original sides of both cities, and there is some comparison and learning functions, but there is no effective situation under certain limitations (such as: an active effort that ensures the continuity of collaborations is not given, focusing more on studies focusing on the city, lack of cooperation based on projects, existence of human resources and organizational deficiencies to perform these activities, budget deficiencies, etc.).

1 Bu makale, ilk yazar tarafından "Kardeş Şehir Ilişskileri ve Öğrenen Kentler: Trabzon Büyükşehir Belediyesi Örneği” başlığında Dr. Öğr. Üyesi Levent MEMİ̧ danışmanlığında hazırlanan ve Giresun Üniversitesi, SBE, Siyaset Bilimi ve Kamu Yönetimi Bilim Dalı'nda yüksek lisans tezi olarak kabul edilen metinden üretilmiştir. 


\section{GIRISS}

Ekonomik, sosyal, teknolojik vb. değişkenlerin etkisi altında yeni sorun ve ihtiyaçlarla karşılaşan yerel yönetimler, gerek kendine fayda sağlama gerekse de ortak bir meselenin çözümüne paydaş olmak amaciyla ulusal veya uluslararası düzeyde iş birliklerine daha fazla ihtiyaç duymaktadır. Adı geçen iş birlikleri, günümüz açısından biçimsel ve biçimsel olmayan türleriyle karşılığını bulmaktadır. Yerel düzeyde, iki kent arasında biçimsel olarak gerçekleşen iş birliklerinden biri de kardeş kent (Town Twinning / Sister City) uygulamasıdır. Farkl1 ihtiyaçlardan hareketle gündeme geldiği anlaşılan kardeş kent ilişkisinin geçmişi geriye götürülmekle birlikte, ağırlıklı olarak İkinci Dünya Savaşı'ndan sonra Batı Avrupa merkezli yaygınlık kazanmaya başladığ anlaşılmaktadır. Uygulamanın bu dönem açısından çıkış noktası, toplumlar arasında barışı ve huzuru sağlayacak arac1 bir rol yüklenmesinden kaynaklanmaktadır. Hatta bu dönemde kardeş kent uygulamalarının yaygınlaştırılması amacıyla çeşitli oluşumların (Avrupa Belediyeler Konseyi, Birleşmiş Kentler Örgütü gibi) da ortaya çıkarak faaliyetlerde bulunduğu bilinmektedir. Uygulama, 1980 sonrası Batı Avrupa ülkelerinin dişına doğru yayılmaya başlamıştır. Bu tarih, aynı zamanda uygulamanın Türkiye'de de ortaya çıtığı dönemdir.Türkiye Belediyeler Birliği gibi kurumların desteğiyle uygulama yaygınlık kazanmaya başlamıştır.

Kentler arasında biçimsel iş birliğinin aracı olarak kardeş kent uygulamasını çeşitli açılardan araştırmanın konusu yapmak mümkündür. Bu çalışmada kardeş kent olgusu, kentler arası kıyaslamanın (bencmarking) ve öğrenmenin bir aracı olarak konumlandırılmaktadır. İş birliği içinde olan iki kentin belirli ölçütler üzerinden kendilerini kıyaslaması, fazlalık ve eksikleri ortaya çıkararak bir öğrenme aracına dönüşebilmektedir. İfade edilenler bağlamında çalışmanın temel amacı, Türkiye'de ortalama kırk yıldır karşılık bulan kardeş kent uygulamasının, kentler arasında kıyaslamanın ve öğrenmenin (ekonomik, sosyal, kültürel, çevresel, altyapı vb.) bir aracı işlevi bağlamında incelemektir.Belirlenen amaç çerçevesinde TBB'nin kardeş kentleri (Zigetvar ve Dortmund) üzerinden bir inceleme gerçekleştirilmektedir. Verilerin elde edilmesinde dokümanlardan yararlanılmakta ve ilgili taraflarla mülakat gerçekleştirilmektedir.

\section{KAVRAMSAL INCELEME: KIYASLAMA, ÖĞRENEN ÖRGÜTLER, ÖĞRENEN KENTLER VE KARDEŞ KENT UYGULAMASI}

\subsection{Kiyaslama (Benchmarking)}

Uluslararası literatürde "benchmarking" olarak kullanılan kavram Türkçeye "klyaslama" olarak çevrilmekte ve bu şekilde kullanıldığı görülmektedir.Yaygın olarak işletme bilimi alanında öne çıkan kavram, daha iyi bir durumu/örneği hedef alarak karşılaştırmaları ve uyarlamaları kapsayan bir yönetim anlayışı olarak yerleştiği (Doğan ve Demiral, 2008:2) anlaşılmaktadır. Yani kıyaslama uygulaması bir yönetim tekniği ve aracı olarak kabul görmektedir (Demirkan, 2004:6; Budak ve Budak; 2018:100). Bugünkü anlamda ilk kez 1980'lerde Japonya'da kullanılmaya başlandığı ifade edilmektedir (Küçük, 2012:46). Bu anlamda bilinen ilk kıyaslama uygulaması, Xerox işletmesinin diğer Japon işletmelerinin ürettiği fotokopi makinelerini incelemesi sonucu kendi üretimine katması ve başarılı sonuçlar elde etmesiyle olmuştur (Liang, 2005:22'den akt.: Doğan ve Demiral, 2008:3).

Çeşitli tanımlamalar yapılmakla birlikte Koçel (2007:313) kıyaslamayı;

"bir işletmenin, sürekli olarak ve bilinçli bir şekilde, kendi dallarında ve sektörlerinde en iyi (başarılı) olan işletmelerin belirli işleri nasıl yaptıklarını araştırması, incelemesi, kendi usulleriyle karşılaştırarak sonuç çıkarması, çıkardiğı bu sonuçları bir uygulama planı çerçevesinde uygulayarak daha yüksek bir başarı düzeyine ulaşma çabaları",

şeklinde tanımlamaktadır. Diğer bir ifadeyle kıyaslama örgütlerinden etrafındaki iyi uygulamaları görerek, farklı alanlarda/konularda (maliyet, kalite, memnuniyet, vb.) öğrenme çabalarıdır (Koçel, 2007:313). Bu noktada kıyaslamanın temel kavramları: rekabet, ölçüm, yeni düşüncelere açık olma, yenilik öğrenme, müşteri tatmini ve sürekli gelişim olarak öne çıkmaktadır (Demirkan, 2004:8-9). Kıyaslamanın şu özellikleri öne çıkmaktadır (Koçel, 2007:314-315; Demirkan, 2004:13'den akt.: Küçük, 2012:56; Özer, 1999:20-21; Karalar ve Yılmaz, 1998:56-57'den akt.: Mert, 2006:7; Seymen ve Bolat, 2002:182-185);

- Kıyaslama, spesifik konu ve uygulamaları gerekli kılmaktadır.

- Kıyaslama, taklit etme süreci değildir ve sürekli bir arayışın ifadesidir.

- Kıyaslama, sadece pazar analizinde kullanılabilecek bir kavram değildir. 
- Kıyaslama, taraflar arasında ortaklığa ve karşı1ıklı yararlanmaya dayanmaktadır.

- Kıyaslama, liderlik pozisyonuna odaklanmaktır.

- Kıyaslama, rakiplerin yanında farklı sektörlerden farklı ölçeklerde örgütlerin araştırılmasında veya örgütün kendi içinde yararlanabileceği bir araçtır.

- Kıyaslama, somut çıktıların ötesinde süreçler üzerinde de yoğunlaşmaktadır.

Kıyaslama, örgütler için en iyiyi uygulamada bir araç olarak düşünülebilir. Günümüzde örgütler için değişen ve gelişen çevreye ayak uydurmak çok önemli hal almıştır. Bunun içinde kendi içinden ve çevreden yeni şeyler bulmak ve uygulamak hayati öneme sahip olmaktadır. Bu çerçevede uygulama süreci içinde kıyaslamanın farklı türlerinin ortaya çıktı̆̆ görülmektedir. Bu bağlamda kıyaslama seçilen ortağa (kuruluş içi, rekabetçi, fonksiyonel ve jenerik kıyaslama olarak alt türlerine ayrılmakta) ve odaklanılan konuya göre (ürün odakl, süreç odakl1, performans odaklı ve stratejik temelli alt türlerine ayrılmakta) farklılaşabilmektedir ${ }^{2}$ (bkz.: Küçük, 2012:61-67; Karataş, 2004:21-26; Özer, 1999:54-58).

Kıyaslama tekniği, aslında örgütlere yenilikleri benimsemeyi ve kendilerini geliştirmeyi zorunlu kılmaktadır. Buradan hareketle kıyaslamayı ilk kez kullanacak örgütlere yönelik birtakım hususlara dikkat çekilmektedir (Küçük, 2012:55; Koçel, 2007:315):

- Değişimin gerekliliğinin kabul edilmesi,

- Kıyaslanacak şeylerin öncesinde tespit edilmesi,

- Örgütlerin hizmet içi eğitimlere önem vermesi,

- Örgüt veya örgütler arası bilgi paylaşımında samimi ve şeffaf olunması,

- Kıyaslamanın basit bir model olarak görülmemesi ve kısa sürede kıyaslamanın fayda sağlanmayacağının bilinmesi,

- Kıyaslama süreçlerine uygun kıyaslama yapılması,

- Örgütlerin elemanlarını kıyaslama yapabilecek donatıya kavuşturması.

\section{2. Öğrenen Örgütler}

Öğrenme, insanın yaşamını sürdürmesinin önemli eylemlerinden biridir. Aynı zamanda öğrenme, yaşanan dinamik ortamda, örgütlerin ayakta kalması ve devamlılığının sağlanması açısından da hayati öneme sahip olmaktadır (Şimşek, 2005:424). Tamda bu noktada öğrenen örgüt kavramı gündeme gelmektedir. Kavramın geçmişi geriye götürülmekle birlikte, Peter M. Senge'nin 1990 yılında çıkarmış olduğu "Beşinci Disiplin" adlı kitabı ile gerçek manada önem kazandığı ifade edilebilir. Bir modelden ziyade bir yönetim uygulamasına karşılık gelen öğrenen örgüt kavramı genel düzeyde, bir örgütte yer alan çalışanların yeni bilgi üretmelerini ve ortaya çıkan bilgilerin de iş süreçlerine aktarılmasına karşılık gelmektedir (Koçel, 2007:331). Senge (2011:403404) ise öğrenen örgütleri, sistem düşüncesi ile hareket eden, örgüt çalışanlarının kişisel uzmanlıkları olan, düşünsel modellere sahip, paylaşılan görüşü oluşturan ve grup öğrenmesi yapabilme özelliklerini taşıan örgütler olarak nitelendirmektedir. Diğer bir ifadeyle öğrenen örgütler, öğrenmenin bilinciyle öncelikle bireylerden başlayan ve örgütsel seviyede öğrenme ile devam eden ve sonunda kendisini yeniliklere adapte etmede sorun yaşamayan örgütlerdir. Öğrenen örgüt üzerinden oluşturulan ortamla birlikte değişen şartlara uyum ve süreklilik sağlanabilecektir. İfade edilenlerden hareketle, kavramla ilgili şu unsurlar öne çıkmaktadır; bilgi yaratmak, öğrenmek, çalışanların bu yöndeki motivasyonu, ulaşılan sonuçları organizasyon bilgisine dönüştürmek ve bu bilgiyi sorun çözmede kullanmak (Koçel, 2007:331). Ayrıca şu dört aşamada gelişim gösterildiği vurgulanmaktadır; bilen örgüt, anlayan örgüt, düşünen örgüt ve öğrenen örgüt (Saruhan ve Yıldız, 2009:220). Temeli bilgi üretmeye (Saruhan ve Yıldız, 2009:220) dayanan öğrenen örgütlerin bazı özellikleri şu şekilde öne çıkmaktadır (Koçel, 2007:334; Calvert vd., 1994:41'den akt.: Öneren, 2008:168);

- Sistematik sorun çözme yeteneğine sahip olunmas1,

- Yeni yaklaşımları denemeye karşı ilgili olunması,

- Geçmiş deneyimlerden ve ilgili konulardaki tecrübelerin öğrenilmesi,

2 Konu hakkında Bkz.: Küçük, 2012:61-67; Karataş, 2004:21-26; Özer, 1999:54-58. 
- Verileri, kullanabilecek duruma getirerek yararlı hale dönüştürülmesi ve ihtiyaç halinde yararlanabilmesi,

- Kararların ve bilgilerin paylaşılmasından dolayı bireyleri ya da grupları cezalandırmayıp öğrenmenin politika haline getirilmesi,

- Takım ruhu ile esnek bir anlayışın benimsemesi,

- Rakip iyi örneklerden öğrenerek üstünlüklerin sağlanması,

- "her tecrübe; gelecekteki öğrenmeye yardımcı olur, faydalı şeyler öğrenme şansı sağlayarak çalışanların motivasyonunu artırır" anlayışına sahip olunması.

- $\mathrm{vd}$.

$\mathrm{Bu}$ açıklamalardan yola çıkarak öğrenen örgütlerin temel özelliğini şöyle ifade edebiliriz: çalışanların katılımının olduğu iş birliğinin temel alındığı ve sürdürülebilirliğin grup çalışmasıyla olabileceğini vurgulayan uygulama temelli bir süreçtir.

\subsection{Yerel Politikalar ve Öğrenen Kentler}

Yerel yönetimler, tüm dünyada kamu yönetiminin en önemli unsurlarından birisidir.Yerelin kendine özgü sorun ve ihtiyaçlarından hareketle oluşturulacak politikalar önem kazanmaktadır. Farklı yerel yönetim birimleri bulunmakla birlikte kentsel alan açısından belediyeler başat bir aktör konumundadır. Fakat ortaya çıkan bazı sorunlar belediyelerden beklenen performansı etkilemektedir. Bu noktada: politikaların kısa vadeli oluşu, değişime direnç, katı bürokratik yapı ve yönetime katılma eksikliği, performans düşüklüğü, kişisel ve örgütsel vizyon eksikliği, öğrenilmiş çaresizlik gibi sorunlar gündeme gelebilmektedir (Yüksel, 2008:367).

Özellikle teknoloji ile birlikte gelişen kentler, kısa vadeli politikalardan görünürde olumlu etkileniyor gibi olsa da uzun vadede olumsuz etkilenebilmektedirler. Kısa vadeli politikalar kentsel gelişme için kalıcı bir çözüm üretemeyebilmektedir. Kısa vadeli kentsel politikalar aynı zamanda kentsel gelişmeyi geriden takip etmek zorunda kalmaktadır. Oysa, kentsel plan ve politikaların, bugüne kadar olduğunun tersine, kentsel gelişmenin önüne geçerek kentleri yönlendirme zorunlulukları vardır (Görmez, 2001:138'den akt.: Yüksel, 2008:368). Yaşanan değişimi dikkate almamak ve hatta direnç göstermek, örgütsel açıdan yerel yönetimleri politika açısından etkisiz kılabilmektedir. Benzer şekilde katı bir bürokratik yapı, yerel yönetimler için önemli bir diğer sorundur. Yerel yönetimler planlama yaparken ve politikalar üretirken bünyelerinde faaliyet gösteren çalı̧̧anlara ve vatandaşlara yeteri kadar danışmama veya onları sürece dâhil etmeme gibi hareketlerde bulunabilmektedir. Diğer taraftan yerel yönetim birimlerinin ve çalışanlarının performanslarını belirleyememek ve bu durumla bağlantılı kaynakların verimsiz kullanımı ve israfların ne durumda olduğunun bilinmemesi de ciddi bir sorun olarak ifade edilebilir (Yüksel, 2008:371).

Yerel yönetimlerin politikalar üretirken bir başka eksik kaldığı nokta ise vizyondan eksikliğidir. Her yerel yönetim biriminin ulaşmak istediği bir hedefi vardır. Bir vizyona sahip olmak, yerel yönetimler için kaynakların etkin kullanımı, gerekli ihtiyaçların belirlenmesi, hizmet getirdiği vatandaşların memnuniyetlerini artırması bakımından son derece önemlidir (Yüksel, 2008:372).

İfade edilenler bağlamında değerlendirildiğinde yerel yönetimlerin en önemli sorunu olarak teknolojiyi ve yenilikleri, tam anlamıyla öğrenememesi gösterilebilir. Öğrenme, sadece bireyler için değil kurumlar için de hayati bir durum teşkil etmektedir. Zira öğrenmeye önem veren örgütlerin ayakta kaldığı, öğrenmeye karşı direnen örgütlerin ise yok olduğu görülen bir gerçektir.Yerel yönetim literatürü incelendiğinde, "öğrenmenin" bir sorun olarak işlenmediği görülmektedir. Oysa yerel yönetim çalışanlarının ve yerel yönetimlerin öğrenme yetersizliği ve isteksizliği, üzerinde durulması ve çözüme kavuşturulması gereken önemli bir sorundur. Öğrenme sorununun giderilmesi, aslında diğer birçok sorunun da giderilmesine ciddi katkılar sağlayabilecektir (Yüksel, 2008:370). İsteksiz olan ve çalı̧̧anları üzerinde gerekli özeni göstermeyen yerel yönetimler için öğrenme, ciddi bir sorun olmaya devam etmektedir. Fakat yerel yönetimlerin içinde bulunduğu sorunlar nedeniyle öğrenme kabiliyetinin geliştirilmesi şarttır (Yüksel, 2008:372). Bu noktada farklı sorun ve ihtiyaçlarla karşı karşıya gelen yerel yönetimler için kentler arası gerçekleştirilen iş birlikleri ve özelde de "kardeş kent" uygulaması, birer öğrenme aracına dönüşebilmektedir. 


\subsection{Kardeş Kent Uygulaması}

Kardeş kent, belirli açılardan farklılıkları bulunan iki şehrin, uluslararası düzeyde farklı konularda ortak faaliyetler yürütmek amaciyla dostça ilişkilerin geliştirilmesidir (Oktay, 2014:13). Bilinen ilk kent eşleştirmesi, Fransa'daki Keighley ile Poix-du-Nord in Nord kentleri arasında Birinci Dünya Savaşı'ndan sonra yapılmıştır (Öktem vd., 2016:53). Gerçek anlamda kardeş kent uygulamalarının ülkeler tarafından hissedilmesi Birinci Dünya Savaş1 sonrası oluşmuştur (Özmen, 2018:56). Özellikle İkinci Dünya Savaşı'nın yıkıcı etkisi ile harap olan Avrupa kentleri arasındaki gerginliği bitirmeyi amaçlayan kardeş kent uygulamaları, bu bakımdan önemli bir rol üstlenmişlerdir. İkinci Dünya Savaşı'nın yıkıcı etkisini hisseden Avrupa, barışın kalıcı olabilmesini sağlamak için kardeş kent ilişkilerine önem göstermiştir (Özmen, 2018:56). Hatta kardeş kent uygulamasını yaygınlaştırmak amacıyla Avrupa Belediyeler Konseyi (CEMR) ve Birleşmiş Kentler Örgütü (UTO) önemli rol üstlenmiştir.Bu iki örgüt kardeş kent uygulamalarına destek vermek için Avrupa'daki yerel yönetimleri incelemiş ve birçok eşleştirme yapmıştır (http://www.twinning.org, 2019).

1950-1960'lı yıllarda kardeş kent ilişkisi aynı zamanda kültürel anlamda bir iş birliğine, 1970'li yıllarda ise ağırlıklı olarak ekonomik ilişkilere dönüştüğü görülmektedir (Özmen, 2018:58). 1980'li yıllara gelindiğinde ise kardeş kent uygulaması, eski Doğu Bloku ve Üçüncü Dünya ülkelerine doğru yayılmaya devam etmiştir (Clarke, 2011:115). Türkiye'de ise kardeş kent ilişkileri 1980-2000'li yıllarda ortaya çıktı̆̆ söylenebilir (Aktulun, 2015:71). 1990'lı yıllardan itibaren gelişme gösteren Türkiye'deki belediyelerin dünyanın çeşitli bölgelerindeki yerel yönetimler ile kurdukları kardeş kent ilişkileri günümüzde önemli bir seviyeye ulaşmış durumdadır (Oktay, 2014:17). İfade edilen gelişmelerin yaşanmasında belediyelerde bulunan insan kaynağının iyileştirilmesi, yabancı dil kullanımının geliştirilmesi, özel birimlerin kurulması, çeşitli örgütlerin (AB, Türkiye Belediyeler Birliği gibi) desteğinin alınması gibi durumların etkili olduğu ifade edilmektedir (Akman ve Akman, 2017:232).

\section{ARAŞTIRMANIN AMACI VE KAPSAMI}

Çalışmanın temel amacı, farklı gerekçelerle kentler arasında gerçekleştirilen bir iş birliği yöntemi olan kardeş kent uygulamasının kıyaslama ve öğrenmenin aracı bir unsuru olarak incelemektir. Şekil 1'de yer verildiği gibi kavramlar ilişkilendirilmekte ve dikkate alınmaktadır.

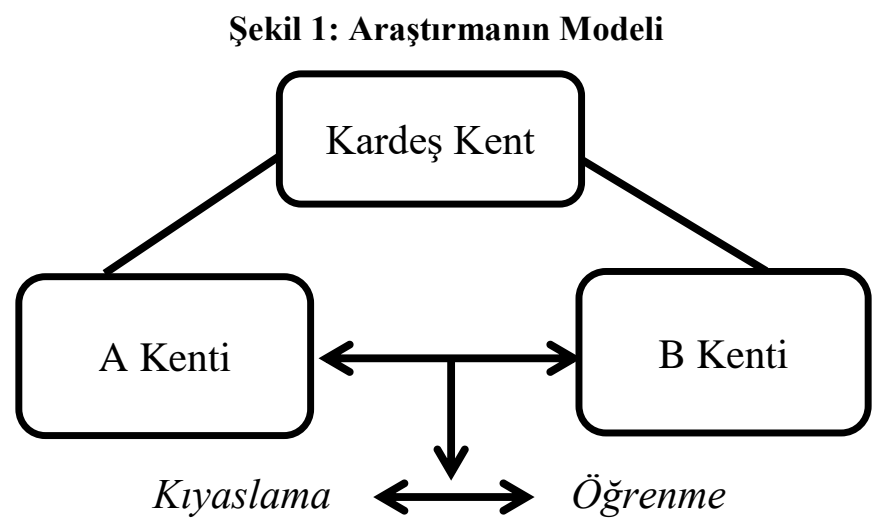

Araştırmanın kapsamını TBB’nin kardeş kent ilişkisi içinde bulunduğu kentler oluşturmaktadır. TBB, ilk kardeş kent ilişkisini 1991 yılında Rusya'nın Soçi kenti ile kurmuştur. Sonraki süreçte sayıları artmıştır (bkz.: Tablo 1). Araştırma dâhilinde, iki farklı kent özelliğini (ekonomik, sosyal ve tarihi açılardan) yansıtan Zigetvar ve Dortmund kentlerine odaklanılmaktadır. 
Tablo 1. Trabzon Büyükşehir Belediyesi ile Kardeș Kent Olan Kentler/ Belediyeler ve Kardeş Kent Protokolünün İmzalandığı Yıllar

\begin{tabular}{|c|c|c|c|}
\hline Kentin Adı ve Ülkesi & Onay Tarihi & Kentin Adı ve Ülkesi & Onay Tarihi \\
\hline Soçi- Rusya & 9 Ağustos 1991 & Zencan- İran & 13 Kasım 2001 \\
\hline Rizhao- Çin Halk Cumhuriyeti & 23 Aralık 1991 & Travnik- Bosna Hersek & 23 Aralık 2005 \\
\hline Zigetvar- Macaristan & 18 Mayıs 1998 & Gabes- Tunus & 6 Haziran 2013 \\
\hline Batum- Gürcistan & 20 Nisan 2000 & Dortmund- Almanya & 1 Haziran 2014 \\
\hline Reşt- İran & 13 Temmuz 2000 & Bişkek- Kırgızistan & 3 Eylül 2014 \\
\hline
\end{tabular}

\section{ARAŞTIRMANIN YÖNTEMI}

Bu çalışmada nitel yöntemlerden olan yarı yapılandırılmış mülakat ve doküman incelemesi gerçekleştirilmiştir. Yarı yapılandırılmış mülakatlar, yüz yüze ve mail ortamında gerçekleştirilmiştir.Bu bağlamda Dortmund Belediyesi ile görüşme 08.05.2018 tarihinde, Dış İlişkiler Ofisi Başkanı Cornelia Irle ile gerçekleştirilmiştir. Görüşmede ses kaydı tutulmuştur ve tercüman yardımı ile görüşme gerçekleştirilmiştir. Görüşme yaklaşık olarak 1,5 saat sürmüştür. Yine Dortmund ile kardeş kent ilişkisinin geliştirilmesinde önemli bir fonksiyonu olduğu tespit edilen TrabzonEv Dortmund Derneği üyeleriyle de 6-7 Mayıs 2018 tarihlerinde görüşmeler gerçekleştirilmiştir. Zigetvar Belediyesi'yle ise 28.11.2017 tarihinde elektronik posta yolu ile görüşme gerçekleştirilmiştir. Zigetvar Belediyesi, Kültür, Gençlik, Sivil ve Uluslararası İlişkiler Komitesi Başkanı Andrea Málek ile iletişime geçilmiştir. TBB ile görüşme 06.11.2017 tarihinde Basın Yayın ve Halkla İlişkiler Daire Başkan Yardımcısı İsmail Saygın ile gerçekleştirilmiştir. Görüşmede ses kaydı alınmış ve yaklaşık 1.5 saatlik bir görüşme gerçekleşmiştir. Görüşme sonrasında konuyla ilgili dokümanlar teslim alınmıştır.

\section{BULGULAR}

\subsection{Tarihi Öneme Sahip Bir Kardeş Kent İlişsisi: Zigetvar Belediyesi ve TBB}

Trabzon ve Zigetvar kentleri arasındaki en önemli ortak nokta tarihten gelmektedir. Sahip olduğu çeşitli özellikleriyle Trabzon, Osmanlı İmparatorluğu'nun onuncu padişahı Kanuni Sultan Süleyman'ın doğduğu yerdir.Zigetvar ise Kanuni Sultan Süleyman'ın öldüğü kenttir. Dolayısıyla iki kent arasında tarihsel bir bağ bulunmaktadır. İlk ilişkilerin 4 Kasım 1994 tarihinde dönemin TBB Başkanı Asım Aykan tarafından Zigetvar Belediyesi'ne, Kanuni Sultan Süleyman'ın 500. yıl dönümü nedeniyle gönderilen bir faxla başladığı anlaşılmaktadır. Cevaben gönderilen yazıda kentle ilgili çeşitli bilgiler verildikten sonra şu ifadeye yer verilmiştir;

“... Tarihi gelenekler bizim için oldukça değerlidir. Kasabamızda tarihi ve diğer nitelikte konferanslar organize edilir. Kültürel, müzik, tarihi ve diğer konularda çok popüler olan ZrinyiFest Program her eylül ayında düzenlenir. 4-5 Kasım'da bizler Sultan Süleyman'ın doğumunun 500.yıl dönümünü kutlarız.Kanuni Sultan Süleyman kasabamızın bir sembolüdür."

Sonrasında bir birini tanıma çalı̧̧malarının ardından sunulan deklerasyonlar çerçevesinde 18 Mayıs 1998 tarihinde resmi olarak iki kent, kardeş kent uygulamasını başlatmıştır.Yaklaşık 11.000 nüfusa sahip olan Zigetvar şehri ile Trabzon şehrinin kardeş kent ilişkisi kurması üzerine iki kent arasında ilişkiler hızlanmış ve kültürel, ticari vs. alanlarda ilerleme olmuştur.

Zigetvar Belediyesi Komite Başkanı (28.11.2017), kardeş kent ilişkisi kurulduktan sonra bu ilişkinin neler amaçladığını şöyle ifade etmiştir:

- İki kentin vatandaşlarının birbirlerinin şehirlerini, geçmişlerini, şimdiki yerlerini ve geleceğini tanımasını mümkün k1lmak,

- Kültürel işbirliğine ve kültürel mirasın korunmasına yardımcı olmak, 
- Eğitim, sağlık ve spor alanlarındaki iş birliğine katkıda bulunmak

- Ekonomi ve turizm alanında ilişkiler kurmak.

Bu kardeş kent ilişkisi Trabzon için gönül bağ 1 kurmak iken Zigetvar için daha çok turizm amaçlı olmuştur. Bu noktada TBB Dış İlişkiler Daire Başkan Yardımcısı'na (06.11.2017) göre Zigetvar Belediyesi, kardeş kent ilişkilerinin kurulmaya başladığı ilk yıllarda daha çok ekonomik bağlantılara yoğunlaşmak istediğini şöyle ifade etmektedir;

"Zigetvar nüfusu yaklaşık 11 bin olan bir şehir ama tarihi yönü oldukça ağır basan bir şehir. Bizler Zigetvar'a ziyaret gerçekleştirdiğimizde bizlerden doğal olarak birçok talepleri oldu. Çünkü amaçları ekonomik ilişkiler kurulması yönündeydi. Bir örnek vermek istiyorum. Zigetvar'da bir askeri havaalan var. Eski bir havaalanı ve bizden oranın pistinin, kulesinin, çevresinin tadilatlarına yardımcı olmamı babında bizlerden yatırımcıları Zigetvar'a yönlendirmemizi istediler. Bizde kendimizin buna gücü yetmeyeceğini ama Ticaret ve Sanayi Odasl ile sizleri görüşürrebileceğimizi söyledik ve toplantı yapmalarını sağladık. Faka tbu görüşmelerden sonra çok azda olsa yardım olduysa da tam netice alınamamıştır."

Farklı alanlarda iki kent arasında bazı faaliyetlerin gerçekleştiği anlaşılmaktadır. Bu noktada kültürel açıdan öne çıkan faaliyet Zigetvar' da her yıl Kanuni Sultan Süleyman ile çarpışan komutanın adıyla gerçekleştirilen "Zrinyi Günleri"dir. Bu etkinliğe TBB'den temsilcilerin katılım gösterdiği ifade edilmektedir.Ekonomik açıdan öne çıkan belirgin faaliyetler bulunmamaktadır. Ancak yine Zrinyi Anma Günleri’ne dikkat çeken Komite Başkanı (28.11.2017);

“2016 yılında Trabzon Büyükşehir Belediyesi, Zigetvar'da Zrinyi Anma Günü’nde oranın sakinleri için Trabzon'u anlatan haritalar, seyahat kitaplart ve tanıtım CD'leri ile bir stant kurmuştur. 2018 yılında 20. Yıl dönümünü kutlayacağımız kardeş şehir iliş̧kimizin bize ekonomik anlamda cesaret verdiğini söyleyebilirim. Türkiye’nin Zigetvar'a sağladiğı kaynaklar şehrimizin Türkler için ne kadar önemli olduğunu kanıtlamaktadır. Kültürel ve toplumsal ilişkiler çok önemlidir ve bu ilişkiler turizm ve ekonomik işbirliği, ortak projeler ve yeni firsatlar yoluyla güçlendirilmelidir",

ifadesinde bulunmaktadır. Çevresel açıdan bakıldığında ise Zigetvar şehrinde yapımı gerçekleştirilen TürkMacar Dostluk Parkı görülmektedir. Bu dostluk parkının bir benzeri de Trabzon'da oluşturulmuştur.

İfade edilenler dikkate alınarak değerlendirildiğinde iki kent arasında daha çok kültürel ilişkilerin geliştiği görülmektedir. Bunlardan en önemlisi yukarıda belirtilmiş olan Zigetvar Belediyesi'nin her yıl kutlamış olduğu Zrinyi Günleri etkinliğidir. İki kent arasındaki faaliyetlerin sınırlı düzeyde kalmasında bazı farklılıklar öne sürülmektedir. Bu noktada TBB Daire Başkan Yardımcısı (06.11.2017);

"Trabzon yaklaşlk 800.000 nüfusu olan ve ticaret yolları üzerinde bulunan, ekonomik durumu iyi olan büyük bir kentken Zigetvar ise yaklaşık 11.000 nüfusu olan bir kasabadır. Doğal olarak iki şehir arasında ciddi manada ekonomik bir uçurum vardur. Zigetvar şehrini çekici kllan tek şey ise 1566 Zigetvar Savaşı'ndan bu güne kalan tarihi önemidir. Ayrıca iki şehir arasındaki mesafenin de oldukça uzak olması bu ilişkinin gelişmesi önünde önemli bir engel teşkil etmiştir",

ifadesinde bulunmaktadır.

\subsection{Dortmund Belediyesi ve TBB Arasındaki Kardeş Kent İliş̧kisi}

Dortmund şehri birçok 1rktan toplulukların yaşadığı özel bir kentdir. Dortmund şehri, Almanya'nın Ruhr Bölgesi'nde bulunan, Kuzey Ren-Vestfalya eyaletine bağlıve 1100 yıllık tarihiyle "Vestfalya'nın kalbi" olarak kabul edilir. Almanya'nın önemli demir-çelik sanayi merkezlerinden birisi olan Dortmund ülke ekonomisine ciddi katkılar sunan bir kenttir (https://www.dortmund.de, 2019). Dortmund şehrinde, Dortmund Belediye Başkanı'nın ifade ettiği üzere 180'den fazla ülkeden insan yaşamaktadır (Dış İlişkiler Ofis Başkanı, 08.05.2018). Dortmund kentinde yaşayan azınlıkların büyük bir çoğunluğunu da Karadeniz Bölgesi'nden ve Trabzon'dan gelen göçmenlerden oluştuğunu ifade eden Dortmund Dış İlişkiler Ofisisi Başkanı;

"Bu durum, Trabzon ve Dortmund şehirleri arasındaki etkileşimi kaçınılmaz kılmıştır. Dortmund'da yoğun bir Türk nüfus yaşamaktadır ve bunlartn çoğunluğu Trabzon ve civarından olan kişilerdir. Trabzonlular tarafindan burada kurulan bir derneğin halen daha aktif bir şekilde faaliyet gösterdiğini ifade etmem gerekiyor. Zira bu dernek faaliyetleri ile bize bir kardeşs şehir kazandirdl", 
KURUTÇU, Koray ve MEMIŞ, Levent - Kıyaslamanın (Benchmarking) ve Öğrenmenin Aracı Bir Unsuru Olarak Kardeş Kent Uygulaması

şeklinde açıklamaktadır. Anlaşılacağı üzere kardeş kent ilişkisinin geliştirilmesinde bir derneğin (TrabzonEv Dortmund) aracı rolü bulunmaktadır. TrabzonEv Dortmund Derneği, Nisan 2002 yılında kurulmuştur. TrabzonEv Dortmund Derneği’nin Yönetim Kurulundan bir üye derneğin amacını şöyle ifade etmektedir;

"2002 yll içerisinde Dernek yöneticilerinin Dortmund ve çevresini gezmeleri ve Derneği tanıtma çabaları sonucu 2002 sonunda yaklaşık 150 üye Derneğin çatısı altında buluştu. Dernek üyelerinin amacı Trabzon'u tanıtmak, birlik beraberlik içerisinde olmak, geleneklerimizi ve göreneklerimizi Almanlara tanıtmak ve sevdirmek ve gençlerimize vatan aşkını aşılamaktı."

Derneğin Dortmund'a gerçekleştirdiği faaliyetler üzerinden iki kent arasındaki iş birliğinin ilk adımları atılmıştır. Sonrasında Dortmund heyeti Trabzon'a davet edilmiştir. Bu süreci Dernek Yönetim Kurulu üyesi şöyle ifade etmektedir;

"Dernek olarak bizler yoğun çabalarımı sonucunda Trabzon ve Dortmund Belediyelerini bir araya getirdik. Dortmund Belediye Heyeti oraya gitmeden bizler Trabzon hakkında kendileriyle fikir alışverişinde bulunduk. Trabzon'un eksikliklerini özellikle altyapı, ulaşım, çöp sorunları vb... kendilerine ifade ettik ve kendilerinden Dortmund'da bulunan tesisler hakkında Trabzon Belediye Heyetine bilgiler vermelerini talep ettik..."

Yapılan görüşmeler sonrasında belirlenen konular üzerinden iş birliği içinde çalışılması kabul edilmiştir (Komite Başkanı, 08.05.2018). Trabzon ve Dortmund Arasında Proje Partnerliğine Yönelik Kooperasyon Anlaşması kapsamında; eğitim ve kültür, gençlik ve spor, ekonomi ve bilim konularında bilgi pylaşımı ve iş birliği, belediyeyle ilişkili konularda ise değişim ve staj programlarının düzenlenmesi gibi çalışmalar planlanmıştır.

Trabzon ve Dortmund arasında yapılan iş birliği protokol anlaşmasından sonra ilişkilerde ciddi anlamla bir gelişme görülmüştür. 2014 yılında iki kent arasında imzalanan kardeş kent protokolleri sonucunda iki kent resmi olarak kardeş kent olmuştur. Bununla ilgili TrabzonEv Dortmund Derneği eski Başkanı şunları ifade etmektedir;

“ Uzun uğraşlar sonucu Dortmund Belediye Meclisinden geçen Trabzon'un Dortmund'un kardeş şehri olabilir kararından sonra gerek Derneğimiz gerekse Mecliste bulunan Türk dostlarımız çok büyük çabaların içerisine girdiler. İlişkilerin gelişmesi için Dortmund halkının Trabzon'u tanıması gerekiyordu. Bunun için Dortmund'da Trabzon etkinlikleri düzenleme fikrini düşünmeye başladık."

TBB, her y1l Şubat ayı içerisinde "Her Yönü ile Trabzon" etkinlikleri düzenlemektedir. 2016 y1lında ilk kez bu etkinlik yurtdışında ve Trabzon'un kardeş şehri Dortmund'da düzenlenmiştir. 24-28 Şubat 2016 tarihleri arasında Dortmund şehrinde fuar alanında yapılan bu etkinlik iki şehrin kardeş kent ilişkisine verdiği önemi göstermektedir. Bu etkinlik hakkında Komite Başkanı (08.05.2018) şunları ifade etmektedir;

"Dortmund Belediyesi olarak uzun zaman sonra kardeşşshir ilişsisi bağlamında bir şehir ile bir bağ kurduk. İki şehrin de samimi olmaları ve ortak yönlerimizin çok olması neticesinde sürekli yapıcı bir tutum sergiledik. Trabzon etkinliklerinin burada yapılmasını biz de çok istedik çünkü burada yaşayan azınlıkların büyük çoğunluğunu Türkler oluşturuyor ve Trabzonlu insanlar bir hayli çoğunlukta."

Her Yönü ile Trabzon etkinliğinin Dortmund şehrinde yapılması hakkında Dernek eski Başkanı (07.05.2018) şunları ifade etmektedir; "Dortmund şehrinde yaşayan Trabzonlular olarak bu etkinliklerin burada yapılmasının mutluluğunu ifade etmemiz olanaksız. Burada yaşayan tüm Türkler bu gelişmeyi memnuniyetle karşıladı". Yönetim Kurulu Üyesi (07.05.2018) ise Dortmund şehrinde yapılan etkinlik için şunları ifade etmektedir; "Uzun yıllar boyunca verilen mücadelenin böylesine özel bir etkinliğin Dortmund şehrinde yapılmast ile desteklenmesi bizleri kardeş şehir ilişkilerimizin kuvvetlenerek artacağına olan inancımızı artırdı.Adeta bir hayalimiz gerçekleşmişti".

Kardeş kent iş birliği içinde farklı çalışmaların yürütüldüğü tespit edilmektedir. Bu bağlamda iki şehrin Ticaret ve Sanayi Odaları arasında, 2010 yılında Dortmund kentinde iş birlikteliği konuları görüşülmüştür. Yapılan görüş̧melerde Dortmund Sanayi Odası Heyeti'nin, Trabzon'da Hidro Elektrik Enerji (HES) yatırımlarıyla ilgilendiklerini, Trabzon Heyeti ise çimento ve metal sektöründe Trabzon'un avantaj taşındığını, bu alanda yatırımların yapılabileceği konusunu gündeme getirmiştir. Dortmund Ticaret ve Sanayi Odası temsilcileri, Üniversite-Sanayi işbirliğinde tecrübelerini Trabzon'a aktarabileceklerini belirttiği anlaşılmaktadır. Ayrıca AB'ye yönelik ortak projelerin gerçekleştirmesi gündeme getirilmiştir. Diğer taraftan Trabzon heyetinin Dortmund ziyaretleri sırasında bir teknik lisede incelemelerde bulunduğu, eğitim kapsamında Trabzon'da 4 
okulla ortak proje ve karşılıklı öğretmen ve öğrenci değişikliği konularında anlaşmaya varıldı ifade edilmektedir (Trabzon Ticaret Gazetesi, 2010:17).

24-28 Şubat 2016 tarihleri arasında Dortmund şehrinde "Her Yönü ile Trabzon" etkinliği düzenlenmiştir. Bu etkinlik ile birlikte Trabzon ve Dortmund arasındaki iş birliği daha da önem kazanmıştır denilebilir. 4 gün süren etkinlik Dortmund'da yaşayan Almanlar ve diğer ülke vatandaşlarının katılımları ile dostane bir şekilde sona ermiştir. Fakat sonraki dönemde iş birliği sürecinin sekteye uğradığı anlaşılmaktadır. Komite Başkanı (08.05.2018) bu durum hakkında şunları ifade etmektedir;

"Dortmund Belediyesi olarak Trabzon’u çok önemsedik. Kardeş şehir ilişkisi kapsamında öğrenci değiş̧im anlaşmaları yaptık ve burada farklı zamanlarda Trabzon'dan gelen meslek lisesi ögrencilerini ağırladık. 2016 yılında Dortmund'da Trabzon Günleri düzenlendi fakat son zamanlarda Trabzon Belediyesi ile iletişime geçemiyoruz."

İş birliğinde yaşanan kopuklukla ilgili olarak TBB Daire Başkan Yardımcısı (06.11.2017) şunları ifade etmektedir;

“2016 yılında Dortmund'da Her Yönü Ille Trabzon Etkinlikleri düzenledik. Büyükşehir ve çevre belediyelerimiz, folklor ekibimiz ve Trabzon'un meşhur lezzetlerini tanıtmak üzere ustalarımız Dortmund şehrinde hazır bulundu. Trabzon Büyükşehir Belediyesi, gelişmekte olan bir belediyedir. Şu an kardeş şehirlerimiz ile yeterli seviyede ilgilenemiyoruz çünkü buna ayırabilecek maddi gücümüz yok. Zamanla Trabzon'da planladı̆̆ımı projeler bittikten sonra kardeş şehirlerimiz ile ilişkilerimizi geliştirmeyi çok isteriz."

Komite Başkanı (08.05.2018) aynı konuda şunları ifade etmektedir;

"Son zamanlarda Trabzon Belediyesi ile iletişime geçemiyoruz. Kendilerini en son 30 Nisan- 7 Mayls 2018 tarihinde "Youth for Peaceand Democracy Program 2018" etkinligimize davet ettik fakat kendilerinden bir cevap veya katılım alamadık. Sadece kardeş şehirlerimizden Trabzon bu etkinlikte yoktu. Biz Trabzon ile sürekli etkileşim içerisinde olmak ve projeler üretmek istiyoruz lakin Trabzon'un da bizimle proje bazlı çalışmayı istemesi gerekmektedir."

Komite Başkanı (08.05.2018) son olarak Trabzon ve Dortmund arasındaki kardeş kent ilişkisi hakkında şunları ifade etmektedir;

"Dortmund Belediyesi olarak bizler Trabzon'u gerçekten isteyerek kardeş şehir olduk. Burada yaşayan azınlıkları da önemsediğimizi bu kardeş şehir iliş̧kisi ile onlara göstermek istedik. İliş̧kinin kurulma aşaması ve Trabzon etkinliğinin yapılacağı ana kadar her şey gayet pozitif ve yapıcıdl. Lakin son zamanlarda iki şehir arasında iliş̧kiler durma noktasına gelmiş ve bu durum bize endişe vermektedir. Umuyorum ki tekrardan ilişkilerimiz düzelir ve ortak projeler üretme konusunda beraber çalışabiliriz."

TBB Daire Başkan Yardımcısı (06.11.2017) ise aynı konuda şunları ifade etmektedir;

"Trabzon Büyükşehir Belediyesi olarak biz kardeş şehirlerimizi önemsiyoruz. Bunun için yıllardır Türkiye'de düzenlediğimiz Trabzon etkinliklerini ilk kez yurtdlşında kardeş şehrimiz Dortmund'da gerçekleştirdik. Bizim gelişmekte olan bir belediye olmamı ve şehrimizde mevcut sorunların çokluğu sebebi ile kabuğumuza çekildik ve bu sorunları çözmek için uğraşmaktayız. Inanıyorum ki sorunlarımızı çözdükçe kardeş şehirlerimiz ile iletişimimizi kuvvetlendirip kendileri ile ortak projeler üreteceğiz."

Bu durumun böyle olmasında çeşitli sebepler sayılabilir. Bunlar kısaca şöyle özetlenebilir:

- TBB’nin gelişmekte olan bir belediye olması ve kardeş kent ilişkilerine ayırabilecek bütçe ve zamanlarının olmamas1,

- Kardeş kent ilişkileri kapsamında oluşturulacak etkinlik ve faaliyetlerin Çevre ve Şehircilik Bakanlığı iznine tabi olmas1,

- Kardeş kent ilişkilerine yeteri kadar önem gösteren ve proje üretmek amaçlı bir birimin yokluğu sayılabilir. 


\section{GENEL DEĞERLENDIRME VE SONUÇ}

Çalışmada, TBB'nin kardeş kentleri olan Zigetvar ve Dortmund Belediyeleri üzerine odaklanılmış, kıyaslama ve öğrenme kavramları bağlamında bir inceleme gerçekleştirilmiştir. Zigetvar kenti, Trabzon kentine göre ölçeği küçük bir yerleşim alanıdır. Dortmund kenti ise Trabzon ile bazı benzerlikleri bulunan bir yerleşimdir. Bu kentler arasında iş birlikleri incelendiğinde daha çok kültürel temelli olduğu ve kısmen bazı açılardan kıyaslamanın ve öğrenmenin gerçekleştiği anlaşılmaktadır. Örneğin 1998 yılında Zigetvar Belediye heyetinin Trabzon'u ziyareti sonrası yine aynı yıl Trabzon heyeti, Zigetvar'ın daveti ile Zigetvar kentine gitmiştir. Burada gerçekleştirilen görüşmelerde Zigetvar Belediyesi, TBB'den eski bir askeri havaalanı pistinin, kulesinin, çevresinin tadilatını, tıpkı Trabzon havaalanındaki gibi restore etmesini istemiştir. Turizm odaklı kalkınma üzerine konumlandırılan Zigetvar'da bir Türk Evi inşa edilerek turizm potansiyelini güçlendirilmeye çalışılmıştır.

Benzer şekilde 2014 yılında Trabzon ile Dortmund arasında, bir STK'nın aracılığıyla, önemli beklenti ve çabalarla oluşturulan kardeş kent iş birliği üzerinden bazı faaliyetler gerçekleştirilmeye çalışılmıştır. Bu noktada meslek lisesi öğrencilerine yönelik değişim programı uygulanmıştır. Özellikle her iki kentin heyetlerinin ziyaretlerinde, kentlere yönelik bazı hususlar gündeme taşınmış ve bazı incelemeler (geri dönüşüm tesisleri) gerçekleştirilmiştir. Ayrıca üç ay gibi kısa bir sürede hazırlıkları tamamlanan "Her Yönü İle Trabzon" etkinliği Dortmund kentinde gerçekleştirilmiştir. Özellikle bu etkinliğin beklentileri karşılamaması, bazı olumsuzları beraberinde getirmiştir. Bu bağlamda iki yıl boyunca yürütülmeye çalışılan iş birlikleri 2016 sonrası kesintiye uğramıştır. Bu noktada iki kent arasında kurulan kardeş kent ilişkisinin gelişmesinin önündeki engeller şöyle siralanabilir;

a) İletişim eksikliği,

b) Herhangi bir projenin varlı̆̆ının olmaması,

c) TBB'nin kendi projelerine ağırlık vermesi.

Sonuç olarak TBB ve onun kardeş kent uygulamaları üzerinden hareketle ifade edilebilecek hususlar şunlar olabilir;

- TBB'nin kurumsal bütünlüğünü tam olarak sağlayamaması ve gelişmekte olan bir büyükşehir belediyesi olmasından dolayı, Trabzon şehrinin temel sorunlarını çözmeden kardeş kentleri ile ekonomik anlamda bir iş birliği yürütmesi mümkün gözükmemektedir.

- $\mathrm{TBB}$, kardeş kentleri ile daha çok genel düzeyde sosyal ve kültürel yönden bir etkileşim yolunu tercih etmiş ve bu durum da ilişkilerin sürekliliğini engellemiştir.

- TBB'nin daha çok mevcut sorunlarının çözümüne odaklanması, Trabzon'un kardeş şehirlerini ihmal etmesine yol açmıştır.

- TBB, yerel yönetim bakımından eksik olduğu deneyimleri belirleyememiş ve özellikle kardeş kentleri başta olmak üzere diğer önemli kentlerden ulaşım, alt yapı, çevre, kent planlaması gibi konularda öğrenme gerçekleştirememiştir.

\section{KAYNAKÇA}

AKGÜN, Ali Ekber, KESKİN, Halit ve GÜNSEL, Ayşe (2009), Bilgi Yönetimi ve Öğrenen Örgütler, Eflatun Yayınevi, Ankara.

AKMAN, Çiğdem ve AKMAN, Elvettin (2017), "Türkiye'de Kardeş SSehir Uygulamalarının Dört Büyükşehir Belediyesi Üzerinden Nitel Bir Analizi”, Süleyman Demirel Üniversitesi Sosyal Bilimler Enstitüsü Dergisi, S.27, ss.228-254.

AKTULUN, Ece (2016), "Yönetişim Çerçevesinde Ortaklıklar ve Belediyelerin Kardeş Şehir İlişkileri: Ankara Büyükş̧ehir Belediyesi Örneği”, Yayınlanmamış Yüksek Lisans Tezi, Adnan Menderes Üniversitesi Sosyal Bilimler Enstitüsü, Aydın.

BUDAK, Gülay ve BUDAK, Gönül (2018), İşletme Yönetimi, Nobel Yayıncılık, Ankara. 
CLARKE, Nicholas (2011), “Globalising care? Town twinning in Britain since 1945," Geoforum, S.42 (1), ss.115-125.

DEMİRKAN, Makbule (2004), İşletme Yönetiminde Yeni Eğilimler Dizisi: Sorularla Kıyaslama, İstanbul Ticaret Odası Yayını, İstanbul.

DOĞAN, Selen ve DEMİRAL, Özge (2008), "İşletmelerde Stratejik Yönetimin Etkinliğini Artırmada Önemli Bir Araç: Benchmarking”, ZKÜ Sosyal Bilimler Dergisi, S.4 (7), ss.1-22.

GÜNDÜZ, Hasan Basri ve URAL, Ayhan (2001), "Benchmarking Yönteminin Eğitim Örgütlerinde Uygulanabilirliği”, Sakarya Üniversitesi Eğitim Fakültesi Dergisi, S.2, ss.45-52.

KARATAŞ, Murat (2004), “Benchmarking Kavramı ve Hizmet İşletmelerinde Fonksiyonel Benchmarking Uygulama Örneği”, Yayımlanmamış Yüksek Lisans Tezi, KTÜ Sosyal Bilimler Enstitüsü, Trabzon.

KÜÇÜK, Orhan (2012), Kalite İyileştirmede Adım Adım Kıyaslama (Benchmarking), Seçkin Yayıncılık, Ankara.

KOÇEL, Tamer (2007), İşletme Yöneticiliği, Arıkan Basım Yayın, İstanbul, 11.Baskı.

ÖKTEM, Mustafa Kemal, GÖÇOĞLU, Volkan ve TUNÇ, Şebnem (2016), "Kardeş Şehir Uygulamalarının Yerel Politika Transferine Etkisi: Alanya-Gladbeck Araştrması", Çağdaş Yerel Yönetimler Dergisi, S.25(4), ss.49-86.

MERT, Erkut Batuhan (2006), "Benchmarkıng Uygulamalarının Örgüt Performansı Üzerindeki Etkilerine Yönelik Bir Araştırma”, Yayımlanmamış Yüksek Lisans Tezi, Marmara Üniversitesi Sosyal Bilimler Enstitüsü, İstanbul.

OKTAY, Tarkan (2014), “Türkiye'deki Belediyelerin Türk Cumhuriyetleri ile Kardeş Şehir İlişkileri”, Türk Dünyasında "Yerel Yönetimlerin Sorunları” (Ed. Deniz İşçioğlu), Nobel Yayınevi, Ankara, ss.11-29.

ÖNEREN, Melahat (2008), “Işsletmelerde Öğrenen Örgütler Yaklaşımı”, Zonguldak Karaelmas Üniversitesi Sosyal Bilimler Dergisi, S.4 (7), ss.163-178.

ÖZER, Pınar Süral (1999), Benchmarking, Vizyon Yayınları, İzmir.

ÖZMEN, Malik (2018), "Yerel Yönetimlerin Uluslararası İlişkileri ve Bir İşbirliği Modeli Olarak Kardeş Şehirler: İstanbul Büyükşehir Belediyesi Örneği”, Yayımlanmamış Yüksek Lisans Tezi, Marmara Üniversitesi Sosyal Bilimler Enstitüsü, İstanbul.

SARUHAN, Sadi Can ve YILDIZ, Müge Leyla (2009), Çağdaş Yönetim Bilimi, Beta Yayıncılık, İstanbul.

SENGE, Peter (2011), Beşinci Disiplin: Öğrenen Organizasyon Düşünüşü ve Uygulaması, Yapı Kredi Yayınları, İstanbul.

SEYMEN, Oya Aytemiz ve BOLAT, Tamer (2002), Örgütsel Öğrenme ve Kıyaslama (Benchmarking) Tekniğinin Bir örgütsel Öğrenme Aracı Olarak Kullanılması, Ezgi Kitabevi, Bursa.

ŞİMŞEK, M. Şerif (2005), Yönetim ve Organizasyon, Güney Ofset, Konya, 8.Bask1.

TRABZON TICARET GAZETESİ (2010), Trabzon Ticaret Gazetesi, Trabzon Ticaret ve Sanayi Odası Yayın Organ1, S.19 (218).

YÜKSEL, Fatih (2008), “Yerel Yönetim Sorunlarına Farklı Bir Bakış: Öğrenme”, Türkiye'de Yerel Yönetimler (Ed. Recep Bozlağan ve Yüksel Demirkaya), Nobel Akademik Yayıncılık, Ankara, ss.367372.

http://www.twinning.org/en/page/enter-our-universe-of-twinning (Erişim Tarihi: 04.02.2020).

https://www.dortmund.de/de/leben_in_dortmund/start_lid/index.html (Erişim Tarihi: 18.04.2019). 